\title{
MATERNAL WATERPIPE SMOKE EXPOSURE AND THE RISK OF ASTHMA AND ALLERGIC DISEASES IN CHILDHOOD: A POST HOC ANALYSIS
}

\author{
MIRNA WAKED ${ }^{1}$ and PASCALE SALAMEH ${ }^{2}$ \\ ${ }^{1}$ Balamand University, Beirut, Lebanon \\ Pulmonology Department \\ ${ }^{2}$ Lebanese University, Hadath, Lebanon \\ Faculty of Pharmacy
}

\begin{abstract}
Objectives: This analysis was conducted with the objective of evaluating association between waterpipe passive smoking exposure and asthma, and allergies among Lebanese children. Material and Methods: Data were taken from a crosssectional study on children from public and private schools. A sample of 22 schools participated in the study, where standardized written core questionnaires were distributed. From 5 to 12-year-old students filled in the questionnaires at home, while 13-14-year-old students filled it in in the class. In total, 5522 children were evaluated for the prevalence of asthma, allergic rhinitis and atopic eczema, and their associated factors, including waterpipe exposure due to parents' smoking. Results: The descriptive results of parental smoking were, as follows: among mothers: 1609 (29\%) mothers smoked cigarettes, 385 (7\%) smoked waterpipe and 98 (1.8\%) smoked both; among fathers: 2449 (44.2\%) smoked cigarettes, $573(10.3 \%)$ smoked waterpipe and $197(3.5 \%)$ smoked both. Maternal waterpipe smoking was significantly and moderately associated with allergic diseases $\left(\mathrm{p}<0.001 ; \mathrm{OR}_{\mathrm{a}}=1.71\right)$, including probable asthma, rhinitis and dermatitis $(\mathrm{p}<0.001$ for all). Quite on the opposite, father's waterpipe smoking was not associated with any of the diseases. Parental cigarette smoking demonstrated some positive effects: father's cigarette smoking did not show association with dermatitis or asthma diagnosed by a physician, while mother's cigarette smoking showed a positive association only with probable asthma. Moreover, no interactions between cigarette and waterpipe smoking were observed. Conclusions: Maternal waterpipe smoking should be regarded as a high risk behavior; however, additional studies are necessary to confirm this finding.
\end{abstract}

Key words:

Asthma, Allergy, Waterpipe smoke, Cigarette smoke

\section{INTRODUCTION}

Childhood asthma is the most important disease of the childhood [1], which is associated with high morbidity [2]. While its natural history is still largely unknown [3], the risk factors for asthma and other allergic diseases, such as rhinitis and eczema, are currently being investigated [4-8]. So far they have been related to genetic predisposition and environmental exposures $[7,8]$.
We had conducted an epidemiological study in Lebanon, with the objective of determining the prevalence and risk factors of allergic diseases in Lebanese school children. This study indicated the following prevalence data: 5.6\% for diagnosed asthma, 21.4\% for ever wheezing, 32.7\% for allergic rhinitis and $11.5 \%$ for atopic eczema among children 13-14 years old. These results were respectively: $4.8 \%, 14.8 \%, 21.2 \%$ and $11.8 \%$, among children

Received: May 4, 2014. Accepted: July 18, 2014.

Corresponding author: P. Salameh, Lebanese University, Faculty of Pharmacy, Hadath, 961 Beirut, Lebanon (e-mail: pascalesalameh1@hotmail.com). 
aged 5-12. These values were considered among the medium prevalence trend noted all over the world and reported by the International Study of Asthma and Allergies in Childhood (ISAAC) $[9,10]$. A previous analysis had been performed to determine which factors were independently associated with asthma, allergic rhinitis and atopic eczema. It is important to remember that we took into account maternal and paternal smoking, without developing smoking subtypes in this latter publication: we found that mother's smoking was associated with probable asthma $(\mathrm{p}<0.001$; adjusted odds ratio $\left(\mathrm{OR}_{\mathrm{a}}\right)=1.43,95 \%$ confidence interval (CI): 1.23-1.64), allergic rhinitis $\left(\mathrm{p}=0.004 ; \mathrm{OR}_{\mathrm{a}}=1.20\right.$, 95\% CI: 1.06-1.37), but not atopic eczema $(\mathrm{p}=0.13$; $\left.\mathrm{OR}_{\mathrm{a}}=1.14,95 \% \mathrm{CI}: 0.96-1.35\right)$. Similar results were found for father's smoking $\left(\mathrm{p}<0.001 ; \mathrm{OR}_{\mathrm{a}}=1.30\right.$, 95\% CI: 1.14-1.50; and $\mathrm{p}<0.001 ; \mathrm{OR}_{\mathrm{a}}=1.32$, 95\% CI: 1.16-1.49), respectively [11]. Although passive exposure to cigarette smoke is known to be a risk factor for asthma and allergic diseases [12-14], waterpipe smoking effects on health are still largely unstudied. Up till now, still nothing is known about the effect of passive waterpipe smoking on children.

Waterpipe smoking is more and more common among populations of all ages, and is falsely thought to be harmless [15]. The objective of this post hoc analysis was to explore the effect of different smoking types on allergic diseases, with particular emphasis on waterpipe smoking.

\section{MATERIAL AND METHODS}

\section{Study design and procedures}

The study was an analytical cross-sectional study carried out among school children in Lebanon in 2005. After translation into Arabic and back translation into English to ensure questions accuracy, the standardized ISAAC written core questionnaire was used [16,17]. Additional details about the study methodology exist in specific publications $[9,10]$.
A school served as a sampling unit. Thirty schools were randomly selected from a list of schools provided by the Ministry of Education; this number was chosen so as to allow for 6000 questionnaires to be distributed in this age group (if a $66.7 \%$ response rate of schools was to be obtained). Permission from the Ministry of Education ensured an easy access to the public schools, while the private ones could voluntarily participate. Contacts were made with the schools' headmasters to explain the objective of the study and its procedure.

Thirteen public schools were contacted: 1 in Beirut; 2 in South Lebanon; 1 in Nabatieh; 3 in Mount Lebanon; 5 in North Lebanon; 1 in Bekaa. In the case of private schools, 17 were contacted: 6 in Beirut, 6 in Mount Lebanon; 2 in North Lebanon; 1 in Nabatieh; 2 in Bekaa. Eight schools (1 public and 7 private ones) refused to participate, while 22 out of $30(73.3 \%)$ agreed to distribute the questionnaires among their students between the 1st and 9 th grades.

Standardized questionnaires were distributed among children aged 5-12 years who had to take the questionnaire home so that it could be filled in by their parents and returned to school and picked up by the inquirer. The remaining questionnaires were distributed to children aged 13-14 years who were to fill the questionnaire in at school, supervised by the enquirer. No further intervention by the enquirer was required during the questionnaires completion. Afterwards, the questionnaires were collected anonymously from all the age groups.

\section{Variables}

The dependent variables included asthma diagnosed by a physician, assessed by the answer to the question: "Has your doctor ever said you had asthma?". Asthma symptoms such as ever wheezing, last 12 months wheezing, and wheezing on exercise without physician diagnosis, according to ISAAC questionnaire [16] were also evaluated. A probable asthma was defined as physician diagnosed 
asthma or having suffered from any asthma symptoms (ever wheezing, 12 months wheezing or wheezing on exercise).

Allergic rhinitis was also assessed by the question: "Have you ever had a problem with sneezing, or a runny or blocked nose when you did not have cold?". In addition, atopic eczema was considered positive if the individual answered yes to one of the following questions: "Have you ever had eczema?" or "Have you ever had an itchy rash on the folds of the elbows, behind the knees, in front of the ankles, under the buttocks, or around the neck, ears or eyes?". Moreover, any kind of allergic disease was defined as having probable asthma, diagnosed asthma or allergic rhinitis, or atopic eczema.

A particular attention was paid to waterpipe smoke exposure due to parental smoking, considered as a major independent variable. Questions about paternal and maternal smoking were asked: "Does your father smoke?", "Does your mother smoke?"; information on the type of smoking was also collected (waterpipe, cigarette or both), just as the number of smoked cigarettes per day and the number of waterpipe smoked per week, where applicable.

Other independent variables were: age, school type, sex, parental education, and potential risk factors of asthma and allergic diseases, such as parental cigarette smoking, parental respiratory problem, infancy gastroesophageal reflux, recurrent otitis, bedroom carpet presence, humidity in bedroom, animal possession, type of mattress and pillow, heating manner. They were all considered as potential confounders.

\section{Statistical analysis}

The questionnaires were coded and the data were introduced using Statistical Package for Social Sciences (SPSS) software, version 12.0 by independent lay persons. Data entry was then controlled twice, and data analysis was performed by the same SPSS software. Weighting cases was performed according to the population distribution by age group, sex and governate in Lebanon by Central Administration of Statistics [18]. Cluster effect was taken into account according to the method suggested by RumeauxRouquette and collaborators [19].

A p-value $<0.05$ was considered significant. The $\mathrm{Chi}^{2}$ test was used for comparison between categorical variables, while Student's t-test was used for comparison of means between the groups. For multivariate analysis, stepwise backward likelihood ratio logistic regressions were performed in the case of the diseases, taking into account the studied socio-demographic factors and factors that presented a significant or a borderline $(p<0.2)$ association in a bivariate analysis. We ensured model adequacy to the data by the use of the Hosmer Lemeshow test. Adjusted odds ratios $\left(\mathrm{OR}_{\mathrm{a}}\right)$ were then calculated. Waterpipe smoking of a father and a mother were particularly looked at as the exposures of interest; the 1st level interactions between cigarette and waterpipe smoking of a father and a mother were also taken into account. A sensitivity analysis of the results in different age groups was performed (5-12-year-old children vs. 13-14-year-old ones).

\section{RESULTS \\ Descriptive results}

In this study, 7679 questionnaires were distributed, and the overall response rate was $72 \%$. After weighting on distribution by age group, sex and governate in Lebanon, the analysis covering 5544 questionnaires was finally performed. Descriptive results of parental smoking were, as follows: among mothers: 1609 (29\%) mothers smoked cigarettes, 385 (7\%) smoked waterpipe and 98 (1.8\%) smoked both; among fathers: 2449 (44.2\%) fathers smoked cigarettes, 573 (10.3\%) smoked waterpipe and 197 (3.5\%) smoked both.

\section{Socio-demographic characteristics and allergic diseases}

In Table 1, socio-demographic characteristics of the population and different subgroups are presented. Public 
schools $(\mathrm{OR}=1.67 ; \mathrm{p}<0.001)$, higher age categories $(\mathrm{p}<0.001)$, male sex $(\mathrm{OR}=1.36 ; \mathrm{p}<0.001)$, and a father and a mother's lower education $(p<0.001)$ were associated with higher odds of probable asthma, defined as physician diagnosed asthma or asthma symptoms (all wheezing) (Table 1).

\section{Multivariate analysis of allergic diseases risk factors}

Results of the multivariate analyses of allergic diseases risk factors are presented in Table 2. After carrying out the sensitivity analysis, similar $\mathrm{OR}_{\mathrm{a}}$ were found for associations of maternal and paternal smoking with allergic diseases between 5-12-year-old children and those 13-14 years old (the results not shown); thus merged results were reported.

A higher age and male sex were associated with all allergic diseases except for atopic dermatitis; consistent positive associations were found for pertussis during childhood, recurrent otitis, having a heart problem, humidity on bedroom walls, infancy gastroesophageal disease, a father's and a mother's lung disease. Moreover, being in a public school, having a carpet in the bedroom, heating home with diesel fuel and having a pet were positively associated with the majority of allergic diseases, while a cotton mattress seemed protective.

As for parental smoking, waterpipe smoking of the mother was moderately and independently associated with allergic diseases $\left(\mathrm{OR}_{\mathrm{a}}=1.71 ; \mathrm{p}<0.001\right)$; the association, however, did not reach statistical significance with physician diagnosed asthma ( $p>0.05)$. Quite on the opposite, father's smoking of waterpipe did not give any statistically significant associations with allergic diseases.

The father's cigarette smoking was significantly associated with asthma symptoms, allergic rhinitis and any type of allergic disease $\left(\mathrm{OR}_{\mathrm{a}}=1.19 ; \mathrm{p}=0.006\right)$, while the mother's cigarette smoking was only associated with asthma symptoms. One noteworthy point is that no interactions were found between the types of smoking and allergic diseases; only father's and mother's cigarette smoking were significantly associated with physician diagnosed asthma (Table 1).

\section{DISCUSSION}

In this post hoc analysis, classical risk factors for asthma and allergic diseases were found to be similar to what we had previously published [11] and to what is presented in the literature, i.e., male sex [20], age [3], public schools reflecting a lower socio-economic status [21,22] and buildings that are less well entertained than private schools [23], family history of lung diseases [8], heart disease [24], recurrent otitis [25,26], pertussis infection [27,28], infancy gastroesophageal reflux disease [29], the presence of molds on bedroom walls $[3,7,30]$, having a pet and carpet presence in the bedroom (an index for dust mites presence) $[3,7,30,31]$. A thorough discussion on the outcome of variables distribution and on their associated risk factors has been presented in previous publications [9-11]. In our models, our focus was on passive smoking exposure of children. Both the cigarette smoking mother and father were shown to be risk factors for asthma and allergic diseases just as described in the literature $[5,8,12,13]$. However, this is the 1st study to show that waterpipe smoking by the mother is consistently and independently associated with all types of allergic diseases, including asthma symptoms, allergic rhinitis and atopic dermatitis. Moreover, no interaction between cigarette and waterpipe smoking was found. However, we could not assess the dose-effect relationship of this association, since we did not have data about the mothers' frequency of smoking. Therefore, we suggest future studies that could evaluate this relationship. Nevertheless, the chemical composition of waterpipe smoke, which seems to contain toxicants in quantities similar or even higher than cigarette smoke, may give biological plausibility for the associations we found [32-36]. Moreover, waterpipe active smoking was shown to be a cause of several respiratory diseases and cancers [37-39]. 
Table 1. Association between socio-demographic factors and allergic diseases

\begin{tabular}{|c|c|c|c|c|c|}
\hline \multirow{2}{*}{$\begin{array}{l}\text { Socio-demographic } \\
\text { factor }\end{array}$} & \multirow{2}{*}{ 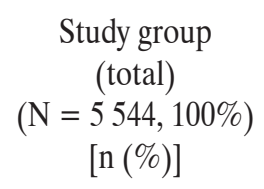 } & \multicolumn{4}{|c|}{$\begin{array}{c}\text { Disease } \\
{[\text { OR }(95 \% \mathrm{CI})]}\end{array}$} \\
\hline & & $\begin{array}{c}\text { probable asthma }^{\mathrm{a}} \\
(\mathrm{N}=1082,19.5 \%) \\
\end{array}$ & $\begin{array}{c}\text { allergic rhinitis } \\
(\mathrm{N}=1360,24.5 \%)\end{array}$ & $\begin{array}{c}\text { atopic eczema } \\
(\mathrm{N}=641,11.6 \%) \\
\end{array}$ & $\begin{array}{l}\text { any allergic disease } \\
(\mathrm{N}=2196,39.6 \%)\end{array}$ \\
\hline \multicolumn{6}{|l|}{ School } \\
\hline public & $1781(32.1)$ & $1.67(1.45-1.92)$ & $1.11(0.98-1.27)$ & $1.10(0.93-1.30)$ & $1.38(1.23-1.55)$ \\
\hline private & $3763(67.9)$ & $\mathrm{p}<0.001$ & $p=0.10$ & $p=0.29$ & $\mathrm{p}<0.001$ \\
\hline \multicolumn{6}{|l|}{ Age (years) } \\
\hline $5-8$ & 1585 (28.6) & 1.00 (ref.) & 1.00 (ref.) & 1.00 (ref.) & 1.00 (ref.) \\
\hline$(>8)-10$ & $1202(21.7)$ & $1.03(0.84-1.2)$ & $1.15(0.96-1.39)$ & $1.03(0.82-1.31)$ & $1.07(0.91-1.25)$ \\
\hline$(>10)-13$ & $1796(32.4)$ & $1.48(1.25-1.78)$ & $1.37(1.16-1.61)$ & $1.00(0.81-1.24)$ & $1.36(1.18-1.56)$ \\
\hline$>13$ & $960(17.3)$ & $\begin{array}{c}2.06(1.70-2.51) \\
p<0.001\end{array}$ & $\begin{array}{c}2.22(1.85-2.66) \\
p<0.001\end{array}$ & $\begin{array}{c}0.98(0.76-1.26) \\
p=0.98\end{array}$ & $\begin{array}{c}2.00(1.70-2.36) \\
p=0.001\end{array}$ \\
\hline Male vs. female & $2890(52.2)$ & $\begin{array}{c}1.39(1.20-1.59) \\
p<0.001\end{array}$ & $\begin{array}{c}1.05(0.93-1.19) \\
p=0.37\end{array}$ & $\begin{array}{c}1.06(0.90-1.27) \\
p=0.44\end{array}$ & $\begin{array}{c}1.19(1.07-1.33) \\
p=0.001\end{array}$ \\
\hline \multicolumn{6}{|l|}{ Father's education } \\
\hline low & $1259(23.4)$ & $1.43(1.19-1.72)$ & $1.15(0.97-1.37)$ & $1.15(0.91-1.45)$ & $1.28(1.10-1.49)$ \\
\hline intermediate & $2518(46.7)$ & $1.09(0.92-1.28)$ & $1.04(0.91-1.22)$ & $1.02(0.83-1.25)$ & $1.08(0.95-1.22)$ \\
\hline high & $1613(29.9)$ & $\begin{array}{l}1.00 \text { (ref.) } \\
\text { p }<0.001\end{array}$ & $\begin{array}{c}1.00 \text { (ref.) } \\
p=0.17\end{array}$ & $\begin{array}{c}1.00 \text { (ref.) } \\
p=0.44\end{array}$ & $\begin{array}{l}1.00 \text { (ref.) } \\
p=0.004\end{array}$ \\
\hline \multicolumn{6}{|l|}{ Mother's education } \\
\hline low & $963(17.8)$ & $1.39(1.15-1.67)$ & $1.14(0.94-1.37)$ & $1.09(0.85-1.39)$ & $1.21(1.04-1.42)$ \\
\hline intermediate & $2659(49.3)$ & $1.02(0.87-1.20)$ & $1.03(0.91-1.19)$ & $0.88(0.73-1.08)$ & $1.02(0.96-1.06)$ \\
\hline high & $1775(32.9)$ & $\begin{array}{l}1.00 \text { (ref.) } \\
\text { p }<0.001\end{array}$ & $\begin{array}{c}1.00 \text { (ref.) } \\
p=0.39\end{array}$ & $\begin{array}{l}1.00 \text { (ref.) } \\
p=0.17\end{array}$ & $\begin{array}{l}1.00 \text { (ref.) } \\
p=0.038\end{array}$ \\
\hline $\begin{array}{l}\text { Child sleeping in his/her } \\
\text { own bed }\end{array}$ & 4824 (87.9) & $\begin{array}{c}0.79(0.65-0.96) \\
\mathrm{p}=0.02\end{array}$ & $\begin{array}{c}0.82(0.69-0.99) \\
\mathrm{p}=0.03\end{array}$ & $\begin{array}{c}0.73(0.58-0.92) \\
\mathrm{p}=0.01\end{array}$ & $\begin{array}{c}0.81(0.69-0.95) \\
\mathrm{p}=0.01\end{array}$ \\
\hline Infancy daycare & $130(23.8)$ & $0.92(0.79-1.08)$ & $1.23(1.08-1.43)$ & $1.11(0.92-1.33)$ & $1.22(1.07-1.38)$ \\
\hline & & $p=0.32$ & $p=0.003$ & $p=0.29$ & $p=0.02$ \\
\hline Electrical vacuum cleaner & 4917 (89.4) & $0.91(0.74-1.13)$ & $1.19(0.97-1.46)$ & $1.08(0.82-1.42)$ & $1.00(0.84-1.19)$ \\
\hline & & $p=0.39$ & $p=0.10$ & $p=0.60$ & $\mathrm{p}=0.97$ \\
\hline \multicolumn{6}{|l|}{ Person per chamber } \\
\hline$>1.6$ & $1826(32.9)$ & $0.99(0.83-1.19)$ & $1.12(0.95-1.33)$ & $0.90(0.72-1.13)$ & $1.08(0.93-1.25)$ \\
\hline $1-1.6$ & $2493(45.0)$ & $1.03(0.87-1.22)$ & $1.12(0.96-1.32)$ & $1.11(0.90-1.38)$ & $1.12(0.98-1.30)$ \\
\hline$<1$ & $1225(22.1)$ & $\begin{array}{c}1.00 \text { (ref.) } \\
\mathrm{p}=0.92\end{array}$ & $\begin{array}{c}1.00 \text { (ref.) } \\
p=0.17\end{array}$ & $\begin{array}{c}1.00 \text { (ref.) } \\
p=0.37\end{array}$ & $\begin{array}{c}1.00 \text { (ref.) } \\
p=0.30\end{array}$ \\
\hline
\end{tabular}

${ }^{\text {a }}$ Probable asthma includes asthma-like symptoms with or without physician diagnosis.

OR - unadjusted odds ratio; $\mathrm{CI}$ - confidence interval.

ref. - reference. 


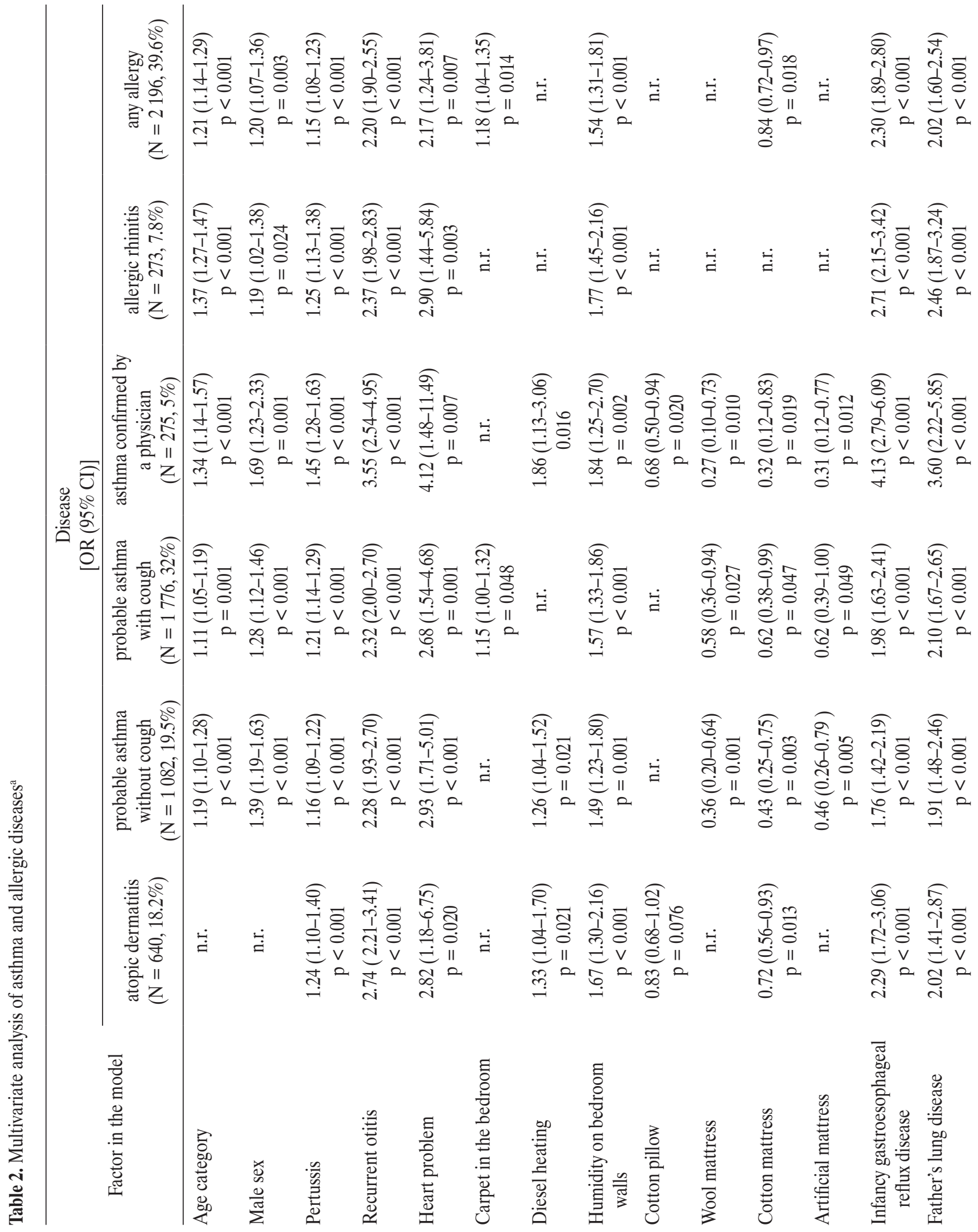




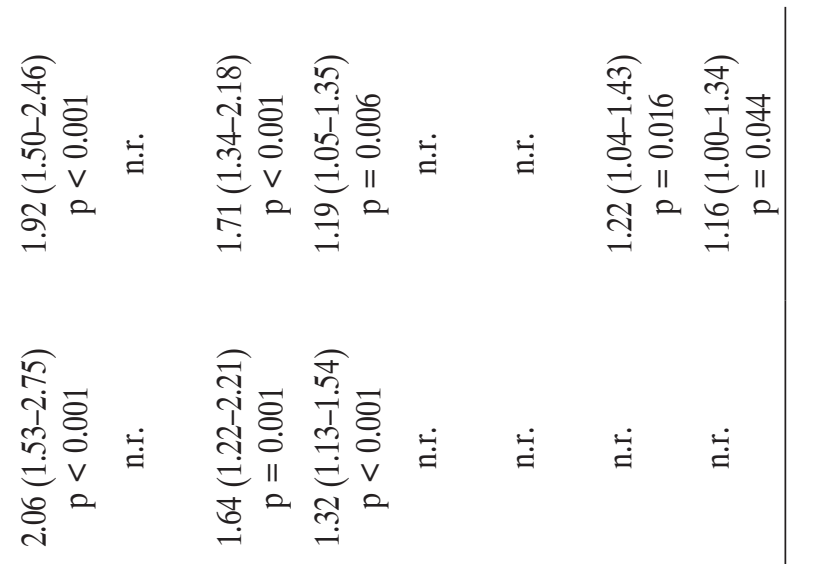

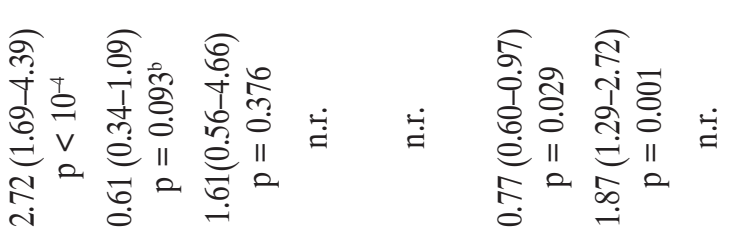

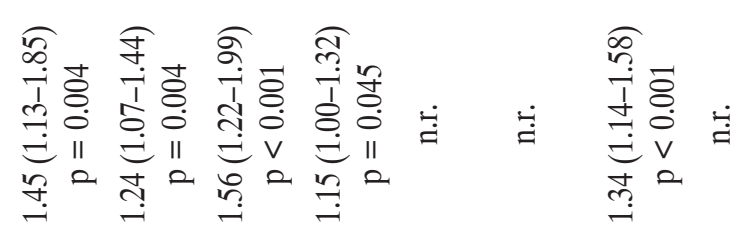

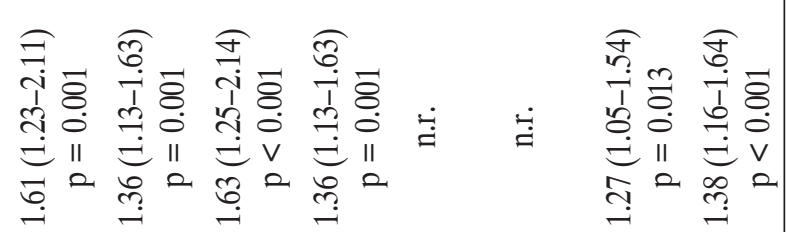

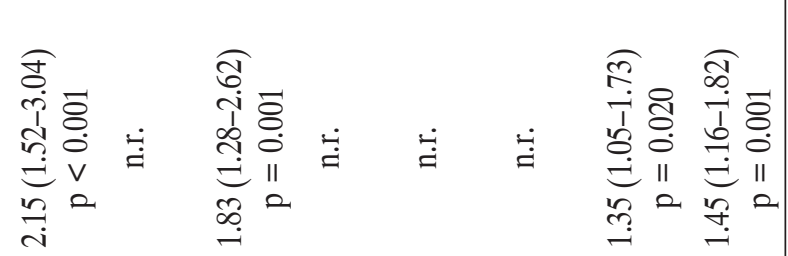

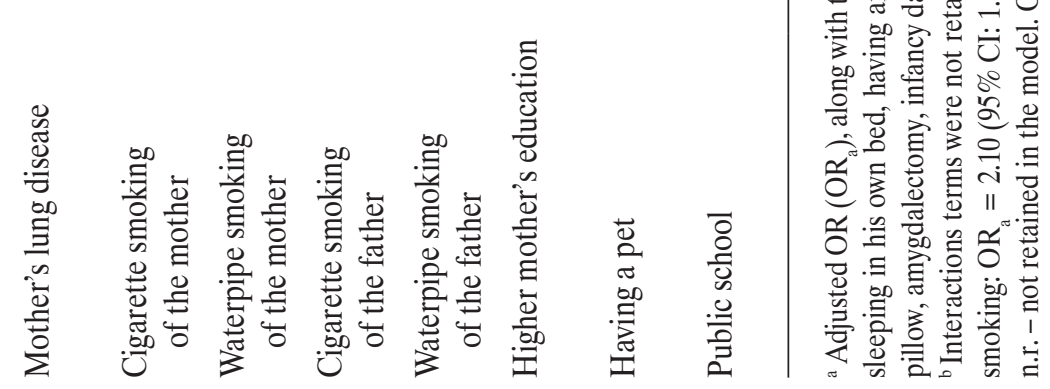


Thus, ongoing research is revealing its harmfulness for health of adults, and this is expected to enhance the plausibility of its effect on children.

Although the fathers' smoking of waterpipe was more common than the mothers', no association was found between the fathers' waterpipe smoking and allergic diseases. This could be explained by social habits of fathers, who meet for waterpipe smoking outside their homes, in the absence of children (in restaurants or cafes), or even inside the houses but away from the children, as it is mostly common in the Middle Eastern regions. Mothers, on the other hand, stay closer to children and therefore, may even not try to avoid their children exposure to passive smoke of waterpipe due to the false belief that waterpipe is harmless [15]. Additional insight into this aspect is suggested in the future studies.

We are aware of the possible biases introduced by this study design. A selection bias is possible because of refusal of some schools to participate in the study. Moreover, since we were exploring data taken from a previous study, we suggest a new data collection with objectives tailored for evaluation of passive smoking exposure for more specific results. Information bias is also possible since the use of a questionnaire in a young population or for surrogate responders (parents) may not always be accurate: problems in question understanding, recall deficiency, and over or under evaluation of symptoms and risk factors may still be possible.

Since the questionnaire was filled in differently by younger and older school children (by their parent at home vs. answered themselves at school), inquiries about the way of understanding the questions and ability to give reliable answers could be generated. However, the carried out sensitivity analysis could partially answer these questions. In addition, some inquiries may refer to the potential risk factors that do not necessarily precede the disease, suggestive of the temporality problem found in the cross-sectional designs. Nevertheless, our methodology is that of other cross-sectional studies, including ISAAC ones, which is necessary for international comparisons.

\section{CONCLUSIONS}

Besides the well-known risk factors for allergic diseases, waterpipe smoking of a mother is found to be a potential risk factor for these diseases too. Although additional studies are necessary to confirm these associations, a mother's waterpipe smoking deserves to be taken into account in prevention and assessment of children with allergic diseases.

\section{REFERENCES}

1. Beasley R; The International Study of Asthma and Allergies in Childhood Steering Committee. Worldwide variation in prevalence of symptoms of asthma, allergic rhino conjunctivitis, and atopic eczema: ISAAC. Lancet. 1998;351:1225-32, http://dx.doi.org/10.1016/S0140-6736(97)07302-9.

2. van Schayck CP, Smit HA. The prevalence of asthma in children: A reversing trend. Eur Respir J. 2005;26(4):647-50, http://dx.doi.org/10.1183/09031936.05.0019805.

3. Porsbjerg C, von Linstow ML, Ulrik CS, Nepper-Christensen C, Backer V. Risk factors for onset of asthma: A 12 year prospective follow up study. Chest. 2006;129(2): 309-16, http://dx.doi.org/10.1378/chest.129.2.309.

4. Koh YY, Kim CK. The development of asthma in patients with allergic rhinitis. Curr Opin Allergy Clin Immunol. 2003;3:159-64, http://dx.doi.org/10.1097/00130832-20030 6000-00002.

5. Biagini JM, Le Masters GK, Levin L, Reponen T, Bernstein DI, Villareal M, et al. Environmental risk factors of rhinitis in early infancy. Pediatr Allergy Immunol. 2006;17(4): 278-84, http://dx.doi.org/10.1111/j.1399-3038.2006.00386.x.

6. Kurukulaaratchy R, Matthews M, Arshad SH. The prevalence, characteristics of an early life risk factors for eczema in 10 year old children. Pediatr Allergy Immunol. 2003;14: 178-83, http://dx.doi.org/10.1034/j.1399-3038.2003.00036.x.

7. Richardson G, Eick S, Jones R. How is indoor environment related to asthma? Literature review. J Adv Nurs. 2005;52(3):328-39, http://dx.doi.org/10.1111/j.1365-2648.200 5.03591.x. 
8. Postma DS, Boezen MH. Rationale for the Dutch hypothesis: Allergy and airway hyperresponsiveness as genetic factors and their interaction with environment in the development of asthma and COPD. Chest. 2004;126:96S-104S, http://dx.doi.org/10.1378/chest.126.2_suppl_1.96S.

9. Waked M, Salameh P. Asthma, allergic rhinitis and eczema in 13-14-year-old schoolchildren across Lebanon. J Med Liban. 2006;54(4):181-90.

10. Waked M, Salameh P. Prevalence of asthma, allergic rhinitis and eczema in 5-12 year old school children across Lebanon. Public Health. 2008;122(9):965-73, http://dx.doi. org/10.1016/j.puhe.2007.10.006.

11. Waked M, Salameh P. Asthma risk factors distribution in Lebanese children. J Asthma Allergy. 2008;2:1-7, http:// dx.doi.org/10.2147/JAA.S3844.

12. Li YF, Langholz B, Salam MT, Frank GD. Maternal and grand maternal smoking patterns are associated with early childhood asthma. Chest. 2005;127:1232-41, http://dx.doi. org/10.1378/chest.127.4.1232.

13. Arshad SH, Kurukulaaratchy RJ, Fenn M, Matthews S. Early life risk factors for current wheeze, asthma, and bronchial hyperresponsiveness at 10 years of age. Chest. 2005;127:502-8, http://dx.doi.org/10.1378/chest.127.2.502.

14. Lieu JE, Feinstein AR. Effect of gestational and passive smoke exposure on ear infections in children. Arch Pediatr Adolesc Med. 2002;156:147-54, http://dx.doi.org/10.1001/ archpedi.156.2.147.

15. World Health Organization Study Group on Tobacco Product Regulation (Tobreg). Waterpipe tobacco smoking: Health effects, research needs and recommended actions by regulators. Geneva: WHO; 2005 [cited 2014 Mar 4]. Available from: http://www.who.int/tobacco/global_interaction/ tobreg/Waterpipe\%20recommendation_Final.pdf.

16. Asher MI, Keil U, Anderson HR, Beasley R, Crane J, Martinez F, et al. International Study of Asthma and Allergies in Childhood (ISAAC): Rationale and methods. Eur Respir J. 1995;8:483-91, http://dx.doi.org/10.1183/09031936.95. 08030483.
17. Lewis TC, Stout JW, Martinez P, Morray B, White LC, Heckbert SR, et al. Prevalence of asthma and chronic respiratory symptoms among Alaska native children. Chest. 2004;125:1665-73, http://dx.doi.org/10.1378/chest.125.5.1665.

18. Central Administration of Statistics. The national study for households living conditions in 2004 [cited 2014 Mar 4]. Available from: http://www.socialaffairs.gov.lb/docs/pubs/ LCH-en.pdf.

19. Rumeaux-Roquette C, Breart G, Padieu R. [Methods in epidemiology: Sampling, investigations, analysis]. Paris: Flammarion edition; 1985. p. 71-82. French.

20. Yeats K, Davis KJ, Sotir M, Herget C, Shy C. Who gets diagnosed with asthma? Frequent wheeze among adolescents with and without a diagnosis of asthma. Pediatrics. 2003;111: 1046-54, http://dx.doi.org/10.1542/peds.111.5.1046.

21. Waked M, Salameh P. Symptoms, severity and asthma control in 5-14 old Lebanon school children. J Med Liban. 2007;55(3):145-51.

22. Corvalan C, Amigo H, Bustos P, Rona RJ. Socioeconomic risk factor for asthma in Chilean young adults. Am J Public Health. 2005;95:1375-81, http://dx.doi.org/10.2105/AJ PH.2004.048967.

23. Education Development Center. Reviving public schools in Lebanon [cited 2014 Mar 4]. Available from: http://www.edc. org/newsroom/articles/reviving_public_schools_lebanon.

24. Massin MM, Astadicko I, Dessy H. Noncardiac comorbidities of congenital heart disease in children. Acta Paediatr. 2007;96(5):753-5, http://dx.doi.org/10.1111/j.1651-22 27.2007.00275.x.

25. History of ear infections and prevalence of asthma in a national sample of children aged 2-11 years. Chest. 2004;125:1685-92.

26. Kwon C, Lee HY, Kim MG, Boo SH, Yeo SG. Allergic diseases in children with otitis media with effusion. Int J Pediatr Otorhinolaryngol. 2013;77(2):158-61, http://dx. doi.org/10.1016/j.ijporl.2012.09.039.

27. Ennis DP, Cassidy JP, Mahon BP. Prior Bordetella pertussis infection modulates allergen priming and the severity of 
airway pathology in a murine model of allergic asthma. Clin Exp Allergy. 2004;34(9):1488-97, http://dx.doi.org/10.1111/ j.1365-2222.2004.02042.x.

28. Dong W, Selgrade MK, Gilmour MI. Systemic administration of Bordetella pertussis enhances pulmonary sensitization to house dust mite in juvenile rats. Toxicol Sci. 2003;72(1):113-21, http://dx.doi.org/10.1093/toxsci/kfg015.

29. Debley JS, Carter ER, Redding GJ. Prevalence and impact of gastroesophageal reflux in adolescents with asthma: A population-based study. Pediatr Pulmonol. 2006;41(5): 475-81, http://dx.doi.org/10.1002/ppul.20399.

30. Te Pas CE, Litonjua AA, Celedon JC, Sredl D, Gold DR. Sensitization to aeroallergens and airway hyperresponsiveness at 7 years of age. Chest. 2006;129:1500-8, http://dx.doi. org/10.1378/chest.129.6.1500.

31. Schram-Bijkerk D, Doekes G, Boeve M, Douwes J, Riedler J, Üblagger E, et al. Nonlinear relations between house dust mite allergen levels and mite sensitization in farm and non farm children. Allergy. 2006;61(5):640-7, http://dx.doi.org/10.1111/ j.1398-9995.2006.01079.x.

32. Sepetdjian E, Shihadeh A, Saliba NA. Measurement of 16 polycyclic aromatic hydrocarbons in narghile waterpipe tobacco smoke. Food Chem Toxicol. 2008;46(5):1582-90, http://dx.doi.org/10.1016/j.fct.2007.12.028.

33. Schubert J, Hahn J, Dettbarn G, Seidl A, Luch A, Schulz TG. Mainstream smoke of the waterpipe: Does this environmental matrix reveal as significant source of toxic compounds? Toxicol Lett. 2011;205:279-84, http://dx.doi.org/10. 1016/j.toxlet.2011.06.017.
34. Shafagoj YA, Mohammed FI, Hadidi KA. Hubble-bubble (water pipe) smoking: Levels of nicotine and cotinine in plasma, saliva and urine. Int J Clin Pharmacol Ther. 2002;40:249-55, http://dx.doi.org/10.5414/CPP40249.

35. Institute for Environment and Health. Indoor air quality in the home: Final report on DETR Contract EPG 1/5/12. IEH Web Report W7. Leicester: IEH; 2001 [cited 2014 Mar 4]. Available from: https://www.cranfield.ac.uk/about/ people-and-resources/schools-and-departments/school-ofapplied-sciences/groups-institutes-and-centres/ieh-reports-/ air-pollution/w7.pdf.

36. Eissenberg T, Shihadeh A. Waterpipe tobacco and cigarette smoking: Direct comparison of toxicant exposure. Am J Prev Med. 2009;37:518-23, http://dx.doi.org/10.1016/ j.amepre.2009.07.014.

37. Akl EA, Gaddam S, Gunukula SK, Honeine R, Jaoude PA, Irani J. The effects of waterpipe tobacco smoking on health outcomes: A systematic review. Int J Epidemiol. 2010;39:834-57, http://dx.doi.org/10.1093/ije/dyq002.

38. Aoun J, Saleh N, Waked M, Salamé J, Salameh P. Lung cancer correlates in Lebanese adults: A pilot case-control study. J Epidemiol Glob Health. 2013;3(4):235-44, http://dx.doi. org/10.1016/j.jegh.2013.06.005.

39. Salameh P, Khayat G, Waked M, Dramaix M. Waterpipe smoking and dependence are associated with chronic obstructive pulmonary disease: A case-control study. Open Epidemiol J. 2012 [cited 2014 Mar 4];5:36-44. Available from: http:/www.benthamscience.com/open/toepij/articles/ V005/36TOEPIJ.pdf.

This work is available in Open Access model and licensed under a Creative Commons Attribution-NonCommercial 3.0 Poland License - http://creativecommons.org/ licenses/by-nc/3.0/pl/deed.en. 